\title{
Progress in the Development of non-BET Bromodomain Chemical Probes
}

\author{
Natalie H. Theodoulou, ${ }^{[a],[b]}$ Nicholas C. O. Tomkinson ${ }^{[b]}$ Rab K. Prinjha ${ }^{[a]}$ and Philip G. Humphreys ${ }^{\star[a]}$ \\ ${ }^{*}$ Corresponding author
}

\begin{abstract}
Bromodomains bind to acetylated lysine residues on histone tails and other proteins. These recognition motifs act with other chromatin associated factors to modulate regulation of gene expression. The Bromodomain and Extra Terminal (BET) family of bromodomains have been the focus of extensive research, leading to the development of many potent, selective chemical probes and recently clinical assets. The profound biology associated with BET bromodomain inhibition has provided a convincing rationale for targeting bromodomains for the treatment of disease. However, the BET family represents just 8 of the 56 human bromodomains identified to date. Until recently, there has been significantly less interest in non-BET bromodomains, leaving a vast area of research and the majority of this new target class yet to be thoroughly investigated. It has been widely reported that several non-BET bromodomain containing proteins are associated with various diseases including cancer and HIV. Therefore, the development of chemical probes for non-BET bromodomains will facilitate elucidation of their precise biological roles and potentially lead to the development of new medicines. This review summarises the progress made towards the development of non-BET bromodomain chemical probes to date. In addition, we highlight the potential for future work in this new and exciting area.
\end{abstract}

\section{Introduction}

Epigenetics describes stable changes in gene expression caused by mechanisms other than those facilitated by alteration to the DNA sequence. ${ }^{[1]}$ Such changes include post-translational modifications (PTMs) of histones, the packaging elements around which DNA is bound. A combination of PTMs creates the 'histone code' and directly influences chromatin structure, access and responses to this information, and therefore, precisely modulates gene expression. ${ }^{[2]}$ Acetylation of lysine residues is one of the most extensively studied modifications of histone tails, regulated by the activity of histone acetyltransferases (HATs) and histone deacetylases (HDACs), which 'write' and 'erase' the acetyl marks respectively. Bromodomain 'reader' modules selectively recognise acetyllysine (KAc) residues in a context sensitive manner and in doing so, recruit the cellular transcriptional machinery to a certain histone mark. As such, bromodomains act together with other chromatin factors to modulate regulation of gene

[a] Miss N. H. Theodoulou, Dr. R. K. Prinjha, Dr. P. G. Humphreys* Epinova Epigenetics Discovery Performance Unit, GlaxoSmithKline R\&D, Stevenage, Hertfordshire, SG1 2NY, U.K.

E-mail: philip.g.humphreys@gsk.com

[b] Miss N. H. Theodoulou, Professor N. C. O. Tomkinson WestCHEM, Department of Pure and Applied Chemistry, Thomas Graham Building, University of Strathclyde, 295 Cathedral Street, Glasgow, G1 1XL, U.K.

\section{transcription. ${ }^{[3,4]}$}

Bromodomains are structurally conserved protein modules consisting of 4 a-helices, linked by two flexible loop regions, which form the KAc binding site (Figure 1). In typical bromodomains, there are two interactions responsible for KAc recognition: a hydrogen-bond between the carbonyl moiety of $\mathrm{KAc}$ and the $\mathrm{NH}_{2}$ of an Asn; and a water mediated interaction to the hydroxyl group of a Tyr. ${ }^{[5]}$ When developing synthetic ligands for bromodomains, it is these interactions that are typically competitively mimicked.

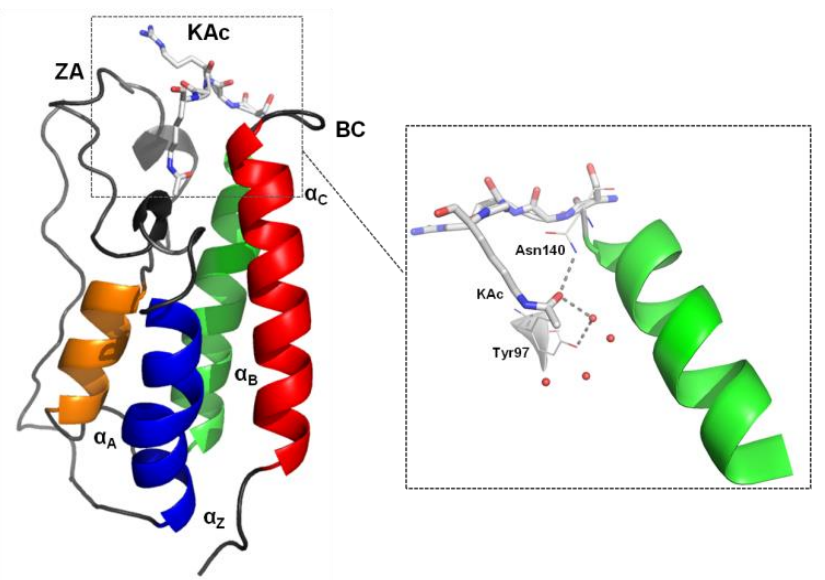

Figure 1. X-ray crystallography of BRD4(1) in complex with histone $\mathrm{H} 4$ (1 $12) \mathrm{K} 5 / 8 \mathrm{Ac}$ peptide (PDB code $=3 \mathrm{UVW}$ ). Hydrogen bonds are shown as grey dashed lines and water molecules as red spheres.

Bromodomains exist as part of bromodomain containing proteins (BCPs), which often contain other domains such as HATs and HDACs. BCPs typically operate as members of larger protein complexes, for example, BRD9 is found as part of the chromatin remodelling SNF/SWI BAF complex. ${ }^{[6]}$ Therefore, the removal of the entire protein by knock-down experiments is a blunt and often misleading tool to investigate protein function. The use of chemical probes, which inhibit a single domain within a protein could show different relevant effects. ${ }^{[7,8]}$ Therefore, inhibition of bromodomains by chemical probes allows their precise biological roles to be determined and validated in the context of disease.

In humans there are at least 56 bromodomains found within 42 BCPs. Each bromodomain has been classified into one of 8 subgroups according to its sequence homology (Figure 2). ${ }^{[1,9,10]}$ There has been significant interest in the Bromodomain and Extra Terminal (BET) family of BCPs (BRD2, BRD3, BRD4 and BRDT), leading to the development of several potent and selective chemical probes. The first chemical probes identified for this class of proteins were structurally related I-BET762 $(\mathbf{1 a})^{[11,12,13]}$ and $(+)-J Q 1(2 a)^{[14,15]}$ in 2010. These compounds allowed exploration of BET bromodomain biology, driving an explosion of interest in this area. Importantly, there are negative control compounds reported for both I-BET762 (1a) and (+)-JQ1 (2a) (16 and $\mathbf{2 b}$ respectively), which have enabled phenotypic screening studies. ${ }^{[7,14]}$ Following the disclosure of I-BET762 (1a) and (+)-JQ1 (2a), several other BET bromodomain chemical 
probes have been identified including: I-BET151 (3) ${ }^{[16,17,18]} \mathrm{PFI}-1$ (4), ${ }^{[19]}$ OX BD $02(5),{ }^{[20,21]}$ MS436 (6) $)^{[22]}$ and RVX-208 (7) ${ }^{[23]}$ [Figure 3 , to aid visualisation of the binding mode, all bromodomain inhibitors in this review display the KAc mimetic (where known) in the top left hand corner]. Inhibitors of the BET family have shown profound anti-cancer and anti-inflammatory properties, with some compounds entering clinical trials. Importantly, the chemical probes reported are from a structurally diverse set of chemotypes, building confidence that the common biological phenotypes observed are driven by BET bromodomain inhibition. As such, inhibition of the BET family of bromodomains has provided a convincing rationale for targeting bromodomains for the treatment of disease. ${ }^{[24]}$

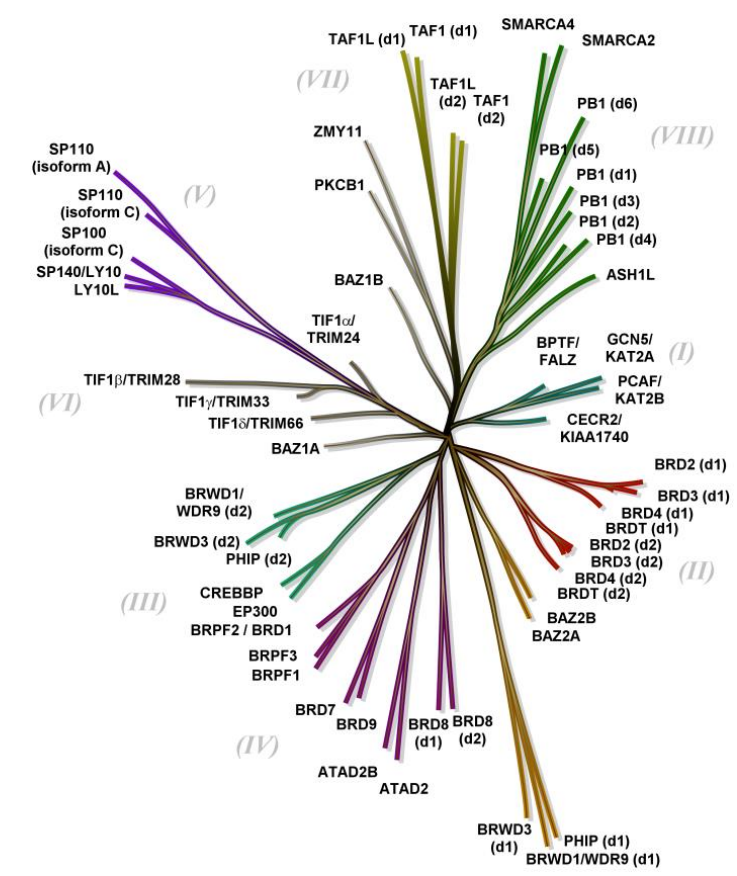

Figure 2. Human bromodomain phylogenetic tree.

\section{Non-BET bromodomain inhibitors}

Despite the important advances within the BET family, the therapeutic potential of the remaining 48 bromodomains is relatively less explored. The development of non-BET bromodomain chemical probes will allow the community to gain a better understanding of their biology and potentially, help to identify and validate new targets for drug discovery. ${ }^{[3]}$ In recent years, there has been significant progress towards this goal, with influential contributions from academic and industrial laboratories as well as the public-private partnership, the Structural Genomics Consortium (SGC). This has resulted in a growing number of chemical probes for non-BET bromodomains, highlighting the intense interest in this area of epigenetic research.

\subsection{Multi-bromodomain inhibitors}

It remains unclear whether multi-bromodomain pharmacology or more selective inhibition is necessary to deliver a relevant phenotype within the context of human disease. The development of both selective and multi-bromodomain inhibitors will help to answer this question. Towards this goal, the SGC and their collaborators have reported a series of multibromodomain inhibitors.

Bromosporine $(\mathbf{8})^{[25]}$ is a non-selective bromodomain ligand (Figure 4). Although the details of the development of $\mathbf{8}$ are yet to be published, the SGC website provides thermal shift data: at $10 \mu \mathrm{M}, \Delta \mathrm{T}_{\mathrm{m}} \geq 3.0^{\circ} \mathrm{C}$ for the bromodomains of the BET family, CECR2, TAF1(2), BRD9 and CREBBP. Bromosporine (8), together with structurally related compound $9,{ }^{[26]}$ are unsuitable as chemical probes for a single bromodomain, due to their polybromodomain pharmacology. However, compounds $\mathbf{8}$ and $\mathbf{9}$ may be enabling as start points towards chemical probes as well as for use in assay development.<smiles></smiles>

$(S)=$ I-BET762 (1a) Pan BET $(R)=(1 \mathrm{~b})$ Negative control<smiles>COc1cc2c(cc1-c1c(C)noc1C)ncc1[nH]c(=O)n([C@@H](C)c3ccccn3)c12</smiles>

I-BET151 (3) Pan BET

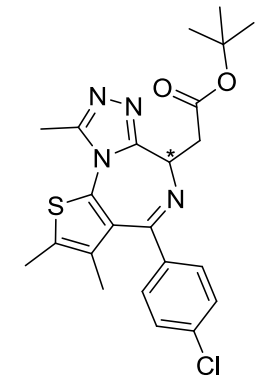

$(S)=(+)-J Q 1$ (2a) Pan BET $(R)=(-)-J Q 1(2 b)$ Negative control<smiles>COc1ccccc1S(=O)(=O)Nc1ccc2c(c1)CN(C)C(=O)N2</smiles>

PFI-1 (4)<smiles>Cc1noc(C)c1-c1cc(O)cc(C(O)c2ccccc2)c1</smiles>

OXF BD 02 (5) Pan BET<smiles>Cc1cc(N=Nc2ccc(S(=O)(=O)Nc3ccccn3)cc2)c(N)cc1O</smiles>

MS436 (6) $\mathrm{BET}(1)$<smiles>COc1cc(OC)c2c(=O)[nH]c(-c3cc(C)c(OCCO)c(C)c3)nc2c1</smiles>

$\mathrm{RVX-208} \mathrm{(7)}$ $\mathrm{BET}(2)$

Figure 3. Chemical structures for selected BET bromodomain inhibitors. 


\subsection{ATAD2}

The ATAD2 BCP is highly expressed in many diverse cancer types and expression levels have been strongly correlated with reduced patient survival and fast disease progression. ${ }^{[27]}$ Although a chemical probe for ATAD2 could represent a useful start point for cancer therapy, the bromodomain has been reported as difficult to drug. ${ }^{[28]}$ In order to target this challenging protein, Fesik and co-workers employed a fragment based screen conducted by NMR spectroscopy. ${ }^{[29]}$ Several chemotypes were identified as novel bromodomain inhibitors, with compound 10 (Figure 4) being the most potent at ATAD2 $\left(\mathrm{K}_{\mathrm{d}}: 350 \mu \mathrm{M}\right)$. X-ray crystallography of 10 in complex with the bromodomain of ATAD2 revealed that the triazole acts as the KAc mimetic.<smiles>CCOC(=O)Nc1cc(-c2ccc(C)c(NS(C)=O)c2)nn2c(C)nnc12</smiles>

Bromosporine (8) Multi-bromodomain<smiles>Nc1cccc(-c2n[nH]c(-c3ccccc3)n2)c1</smiles><smiles>COc1cncc(-c2cnc(NC3CCNCC3)c3[nH]c(=O)c(C)cc23)c1</smiles>

12 ATAD2

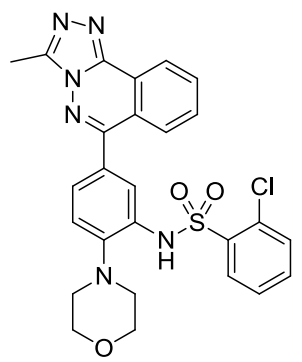

9 BRD4, BRD9, CECR2, CREBBP<smiles>Cc1cn([C@H]2C[C@H](O)[C@@H](CO)O2)c(=O)[nH]c1=O</smiles>

11<smiles>COc1cncc(-c2cnc(NC3CCN(C)CC3OCC3CCC(O)CC3)c3[nH]c(=O)c(C)cc23)c1</smiles>

ATAD2, TAF1(2), TAF1L(2)
Figure 4. Chemical structure for pan-bromodomain inhibitors 8 and $\mathbf{9}$ and ATAD2 fragments 10 and 11.

Knapp and co-workers used a crystallographic fragment based screening approach to identify inhibitors of the ATAD2 bromodomain. ${ }^{[30]}$ Nine crystal structures were reported including that of thymidine (11), which represents a novel KAc mimetic. Compound 11 has an estimated $\mathrm{K}_{\mathrm{d}}$ : $10 \mathrm{mM}$ based on NMR titration experiments. Although the fragments reported exhibit weak binding affinities, these compounds may offer starting points for targeting the bromodomain for ATAD2, a previously un-drugged target.

Most recently, GSK reported compound 12 as the first known micromolar inhibitor of ATAD2. ${ }^{[31]}$ Identified from a fragment-based targeted array derived from a pan-bromodomain fragment, compound 12 shows $\mathrm{IC}_{50}: 1.25 \mu \mathrm{M}$ against ATAD2. Although this compound shows modest activity compared to the potency of some optimised BET inhibitors, this result is significant since ATAD2 is predicted to be one of the least tractable bromodomains. ${ }^{[28]}$ As compound 12 is not selective over the BET family, it was progressed for further optimisation to deliver compound 13, which displays improved ATAD2 activity $\left(\mathrm{IC}_{50}\right.$ : $\left.316 \mathrm{nM}, \mathrm{TR}-\mathrm{FRET}\right)$ and $>160$ fold selectivity over the BET family. ${ }^{[32]}$. However, broader bromodomain profiling by means of BROMOscan ${ }^{[33]}$ revealed that compound $\mathbf{1 3}$ is also active against the second bromodomains of TAF1 and TAF1L. The authors state that the optimisation of this series to generate a cell permeable and significantly more selective ATAD2 chemical probe will be the subject of their next publication.

\subsection{BAZ}

Homologous bromodomains BAZ2A/B belong to the BAZ family of proteins, which are ubiquitously expressed. Little is known about the biological roles of the BAZ family, therefore, the development of chemical probes will help to delineate their function. Despite BAZ2A/B BCPs having low predicted druggability, ${ }^{[28]}$ multiple inhibitors of these domains have been reported. This perhaps highlights the tenacity of medicinal chemists in this area. Ciulli and co-workers describe a fragment based screening approach for the development of BAZ2B inhibitors ${ }^{[34]}$ From a library of 1300 compounds, 10 fragment hits were identified and subsequently crystallized in the bromodomain of BAZ2B. A tetrahydro- $y$-carboline fragment was the most potent and subsequently optimized to deliver compound 14 (Figure 5), which showed an $\mathrm{IC}_{50}: 9 \mu \mathrm{M}$ against BAZ2B (AlphaLISA). Importantly, this work demonstrated the druggability of the BAZ2B bromodomain for the first time.

A collaboration between GSK and the SGC led to the development of GSK2801 (15a), the first selective chemical probe for $\mathrm{BAZ2A} / \mathrm{B} .{ }^{[35]}$ Screening of the BAZ2A bromodomain against a set of molecules that contained KAc mimetics led to identification of the indolizine template, which had been previously reported as an inhibitor of BET bromodomains. ${ }^{[36]}$ An iterative medicinal chemistry design strategy was employed to deliver GSK2801 (15a), which displays $\mathrm{K}_{\mathrm{d}}$ : 257 and $136 \mathrm{nM}$ (ITC) against BAZ2A and BAZ2B, respectively. Selectivity over 46 bromodomains was assessed by thermal shift: at $10 \mu \mathrm{M}, 15 \mathrm{a}$ showed a $\Delta \mathrm{T}_{\mathrm{m}}$ of 4.1 and $2.7^{\circ} \mathrm{C}$ for $\mathrm{BAZ2A}$ and $\mathrm{BAZ2B}$, respectively. Significant shifts were also observed for TAF1L(2) $\left(3.4^{\circ} \mathrm{C}\right)$ and BRD $\left(2.3^{\circ} \mathrm{C}\right)$. These data were supported by biolayer interferometry (BLI) experiments probing the interaction of GSK2801 (15a) against 40 bromodomains, at two concentrations $(0.2$ and $1 \mu \mathrm{M})$. No interaction was detected for the bromodomains of BRD4(1), CREBBP, TRIM24, PB1(5), PCAF or ATAD2, but in agreement with the thermal shift data, BRD9 and TAF1(L) were detected as the major off-targets. To 
test whether GSK2801 (15a), would bind to endogenous BAZ2 proteins, a chemoproteomic competition binding assay was utilized. A linkable analogue of GSK2801 (15a), was immobilized on to a solid support and incubated with nuclear and chromatin enriched HuT78 extracts. Of the 18 endogenous full-length bromodomain proteins that bound to the immobilsed compound, only BAZ2A and BAZ2B displayed a dose-dependent reduction in the presence of GSK2801 (15a). Evidence of cellular target engagement was provided by a FRAP assay in which GSK2801 (15a) displaced BAZ2A/B from chromatin in U2OS cells. In order to determine the suitability of GSK2801 (15a) as an in vivo tool, pharmacokinetic parameters were measured after intraperitoneal and oral dosing to male CD1 mice. GSK2801 (15a) had reasonable in vivo exposure after oral dosing, modest clearance and plasma stability, which should allow the compound to be used as a BAZ2A/B bromodomain inhibitor in vivo. Importantly, this group also developed structurally similar negative control compound $15 \mathrm{~b}$. Compound $15 \mathrm{~b}$ helped to inform chemoproteomics experiments, building confidence that any phenotype observed was not driven by off target activities.

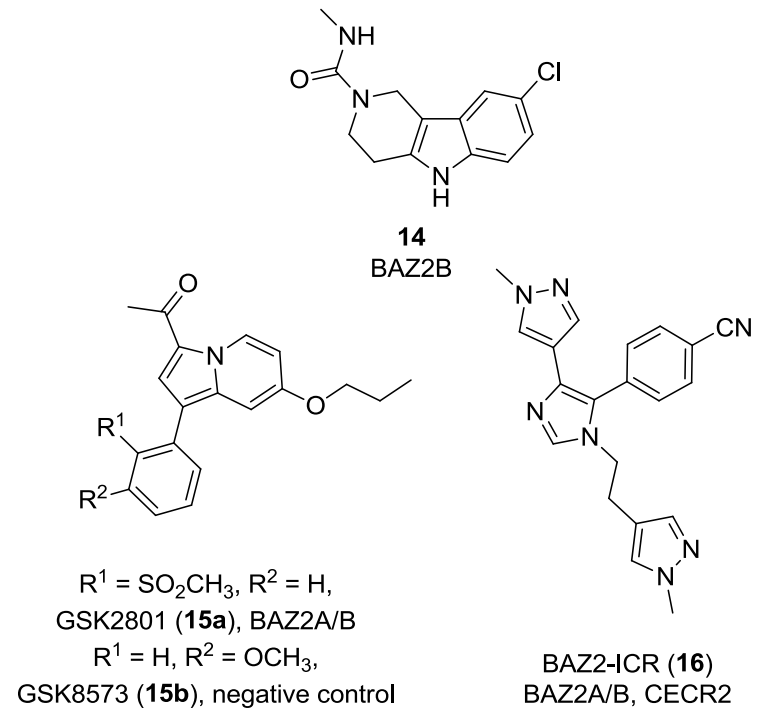

Figure 5. Chemical structures for $B A Z 2 A / B$ bromodomain inhibitors.

More recently, the SGC have collaborated with the Institute of Cancer Research to develop BAZ2-ICR (16) as a chemical probe for BAZ2A/B ${ }^{[37]}$ (Figure 5). BAZ2-ICR (16) was optimized from a single hit identified in a screen of putative bromodomain inhibitors. Compound 16 shows $\mathrm{K}_{\mathrm{d}}$ : 109 and $170 \mathrm{nM}$ against $B A Z 2 A$ and $B A Z 2 B$, respectively (ITC). In agreement with the ITC data, BAZ2-ICR (16) showed $\triangle T_{\mathrm{m}}: 5.2$ and $3.8^{\circ} \mathrm{C}$ for BAZ2A and $B A Z 2 B$, respectively, with no significant shifts against all other bromodomains, except CECR2 $\left(\Delta \mathrm{T}_{\mathrm{m}}: 2.0^{\circ} \mathrm{C}\right)$. ITC experiments revealed a $\mathrm{K}_{d}: 1.55 \mu \mathrm{M}$ at CECR2, showing 15 -fold selectivity. Evidence of cellular target engagement was confirmed by means of a chromatin displacement FRAP assay in U2OS cells. In order to determine the suitability of BAZ2-ICR (16) as an in vivo tool compound, mouse pharmacokinetic data was obtained. The results from these experiments indicated that BAZ2-ICR (16) is suitable for use in vivo, with $70 \%$ bioavailability and moderate clearance ( $50 \%$ of mouse liver blood flow) and volume of distribution.

The chemical probes developed for BAZ2A/B represent an excellent toolset with which the biology can be fully investigated. Importantly, these chemical probes are structurally distinct, in vivo capable and a negative control GSK8573 (15a) is also available for cross validation studies.

\subsection{BRD9}

Until relatively recently there has been very little in the literature concerning the bromodomain of BRD9. However, BRD9 is reported as a component of the chromatin remodeling SNF/SWI BAF complex, which plays a role in regulation of gene expression, providing impetus to develop chemical probes. ${ }^{[6]}$ The first inhibitor of BRD9 was reported by Ley and co-workers, who used flow chemistry to identify a series of compounds

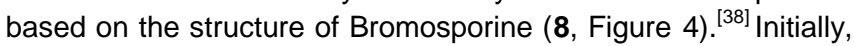
binding to BRD9 was assessed in flow by frontal affinity chromatography coupled with mass spectrometry. This allowed for rapid binding information, which was subsequently confirmed by thermal shift. Of the compound set tested, compound 17 (Figure 6) showed the greatest thermal shift against BRD9 $\left(\Delta \mathrm{T}_{\mathrm{m}}\right.$ : $\left.4.3^{\circ} \mathrm{C}\right)$. However, $\Delta \mathrm{T}_{\mathrm{m}}$ was also seen for BRD4 $\left(6.7^{\circ} \mathrm{C}\right)$, BRPF1 $\left(5.4^{\circ} \mathrm{C}\right)$, BRPF3 $\left(3.1^{\circ} \mathrm{C}\right)$, CECR2 $\left(5.6^{\circ} \mathrm{C}\right)$, CREBBP $\left(4.3^{\circ} \mathrm{C}\right)$, EP300 $\left(8.0^{\circ} \mathrm{C}\right)$, and TRIM24 $\left(1.8^{\circ} \mathrm{C}\right)$.

Filippakopoulos and co-workers have reported the 2amine-9H-purine scaffold as a ligand for BRD9. ${ }^{[39]}$ Through iterative structure based design, compound $\mathbf{1 7}$ was identified as a BRD9 inhibitor. 18 showed $\mathrm{K}_{\mathrm{d}}$ : $0.28 \mu \mathrm{M}$ against BRD9 (ITC), as well as some BRD4(1) activity $\left(\mathrm{K}_{\mathrm{d}}: 1.4 \mu \mathrm{M}\right)$. In order to understand the binding mode of the 2-amine-9H-purine scaffold, attempts were made to obtain an X-ray crystal structure of 18 in complex with the bromodomains of BRD9 and BRD4(1). Although these attempts were unsuccessful, X-ray crystallography of a structurally related analogue indicated occupation of the KAc binding site. Interestingly, the analogue was found to induce a structural rearrangement in the BRD9 binding pocket, resulting in an unprecedented cavity shape. This induced fit could explain the greater BRD9 activity relative to BRD4(1) observed for this template. Docking studies suggest that 18 elicits the same structural rearrangement as observed for the analogue. Cellular target engagement for compound 18 was demonstrated using a NanoBRET assay, ${ }^{[40]}$ in which 18 was found to displace BRD9 from chromatin with $\mathrm{IC}_{50}: 477 \mathrm{nM}$. In addition, 18 is not cytotoxic up to concentrations of $33 \mu \mathrm{M}$. The $9 \mathrm{H}$-purine scaffold offers a template that can be used for further optimization to deliver tool molecules for the bromodomain of BRD9. 
<smiles>Cc1ccc(-c2nn3c(C)nnc3c3ccccc23)cc1NS(=O)(=O)c1ccc(Cl)c(Cl)c1</smiles>

17

BRD9, BRD4, CECR2, CREBBP BRPF1, BRPF3, EP300 and TIF1<smiles>CCn1cc(-c2cccc(C(F)(F)F)c2)c2sc(C(=N)NC3CC[Sb](=O)(O)CC3)cc2c1=O</smiles>

I-BRD9 (19) BRD9<smiles>Nc1nc(-c2cc(Br)cc3c2OCC3)c2nc[nH]c2n1</smiles>

18

BRD9

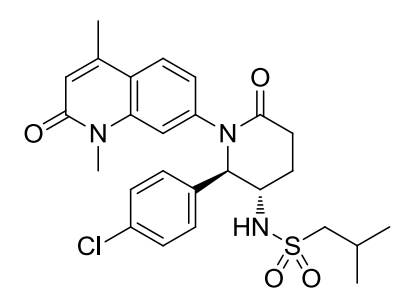

LP99 (20) BRD9/BRD7<smiles>CC(=O)c1cc(-c2cccc3nccn23)c2cc(N3CCOCC3)ccn12</smiles>

21

BRD9/BRD7

Figure 6. Chemical structures for BRD9 inhibitors.

GSK and the University of Strathclyde have reported IBRD9 (19), as a selective, cell penetrant chemical probe for BRD9. ${ }^{[41]}$ The thienopyridone template was identified from a cross-screen of GSK compounds and was subsequently optimized through iterative structure-based design to deliver IBRD9 (19). The compound displays an $\mathrm{IC}_{50}$ : 0.05 and $5 \mu \mathrm{M}$ against BRD9 and BRD4(1), respectively, as determined by TRFRET assay. Broader bromodomain profiling was conducted by means of BROMOscan ${ }^{[33]}$ in which I-BRD9 (19) was tested against a panel of 34 bromodomains. The results from this screen confirmed excellent BRD9 activity $\left(\mathrm{K}_{d} 1.9 \mathrm{nM}\right)$, with $>700$ fold selectivity over the BET family, $>200$ fold over the highly homologous BRD7 ( $\mathrm{K}_{\mathrm{d}}: 380 \mathrm{nM}$ ) and $>70$ fold over every other bromodomain tested. I-BRD9 (19) displaces chromatin from BRD9 in cells with an $\mathrm{IC}_{50}$ : $160 \mathrm{nM}$, providing evidence of cellular target engagement. In addition, I-BRD9 (19) was found to bind to full length, endogenous BRD9 with a $\mathrm{IC}_{50}: 80 \mathrm{nM}$ and $>625$ fold selectivity over BET family member, BRD3. ${ }^{[42], ~[43] ~}$ Selectivity beyond the bromodomain family was also assessed. I-BRD9 (19) was tested in a diverse panel of 49 targets including various enzymes, receptors and ion channels. No activity was observed at less than $5 \mu \mathrm{M}$, providing confidence in the selectivity of this probe molecule. Subsequent cellular studies identified genes involved in oncology and immune response pathways that were selectively modulated by I-BRD9 (19).

The SGC and the University of Oxford reported LP99 (20) as a BRD9/BRD7 chemical probe. ${ }^{[44]}$ LP99 (20) was developed from a fragment exploiting chiral synthesis with diverse building blocks to deliver good BRD9 ( $\mathrm{K}_{\mathrm{d}}$ : $\left.99 \mathrm{nM}\right)$ and BRD7 ( $\mathrm{K}_{\mathrm{d}}$ : $909 \mathrm{nM}$ ) activities, as determined by ITC. Broader selectivity was determined by thermal shift against a panel of 48 bromodomains. LP99 (20) showed excellent selectivity, with $<1^{\circ} \mathrm{C}$ stabilization of all bromodomains except BRD9 and BRD7. Cellular target engagement was assessed by a NanoBRET assay, confirming the ability of LP99 (20) to disrupt binding of BRD9 and BRD7 to chromatin in cells. To investigate the effect of BRD9/7 inhibition on the expression of proinflammatory cytokines, a human THP-1 monocytic cell line was stimulated with lipopolysaccharide. LP99 (20) was found to inhibit production of interleukin 6 in a dose dependent manner.

The SGC website also reports BI-9564 as a BRD9/7 selective chemical probe, developed in collaboration with Boehringer Ingelheim. ${ }^{[45]}$ This probe was discovered through fragment-based screening to deliver excellent activity (BRD9 $\mathrm{K}_{\mathrm{d}}: 14 \mathrm{nM}$; BRD7 $\mathrm{K}_{\mathrm{d}}: 239 \mathrm{nM}, \mathrm{ITC}$ ) and selectivity over the BET family of bromodomains ( $>100 \mu \mathrm{M}$ by AlphaScreen). BI-9564 shows off-target activity against CECR2 in vitro $\left(\mathrm{K}_{\mathrm{d}}: 258 \mathrm{nM}\right.$, ITC), but not in cells (at $1 \mu \mathrm{M}$, FRAP). The structure of BI-9564 has not yet been reported.

Most recently, the SGC and the University of Oxford report compound 21 as a BRD9/7 inhibitor. ${ }^{[46]}$ Using BAZ2A/B chemical probe 15a (Figure 5) as a start point, 21 was developed by optimisation of the 1,3 and 7-positions of the template. Compound 21 was potent at BRD9 $\left(\mathrm{K}_{\mathrm{d}}: 68 \mathrm{nM}\right)$ and BRD7 $\left(\mathrm{K}_{\mathrm{d}}\right.$ : $368 \mathrm{nM})$, with good selectivity over BRD4(1) ( $\left.\mathrm{K}_{\mathrm{d}}: 15 \mu \mathrm{M}\right)$, as determined by ITC. Broader selectivity was assessed by thermal shift in which compound 21 showed $\Delta \mathrm{T}_{\mathrm{m}}: 5.6^{\circ} \mathrm{C}$ against BRD7, with weak affinity for the bromodomains of CBP, p300 and FALZ $\left(\Delta \mathrm{T}_{\mathrm{m}}: 1.8,2.0\right.$, and $1.1^{\circ} \mathrm{C}$ respectively).

Recent efforts towards the development of BRD9 chemical probes has resulted in the identification of several structurally orthogonal inhibitors. As a result of this, the downstream biological effects of BRD9 bromodomain inhibition can be investigated for the first time. Early studies with these probes suggest that BRD9 may play a role in both oncology and inflammation, and as such, provide impetus to further validate these findings.

\subsection{BRPF}

The BRPF family cosists of BRPF $1 \mathrm{~B} / 2 / 3$, which are important scaffolding proteins for the assembly of HAT complexes of the MOZ/MORF family of transcriptional coactivators. It is reported that translocations of $\mathrm{MOZ}$ are associated with aggressive subtypes of leukemia. ${ }^{[47]}$ Chemical probes for the BRPF family of bromodomains have recently been disclosed on the SGC website. OF-1 (22) is a BRPF1B/2/3 selective chemical probe, which displays $\mathrm{K}_{d}$ : $100 \mathrm{nM}, 500 \mathrm{nM}$ 
and $2.4 \mu \mathrm{M}$, respectively (Figure 7). ${ }^{[48]}$ Selectivity against other bromodomains is, in general $>100$ fold. Importantly, the closest off-target bromodomain activity is against BRD4 (39 fold selectivity).

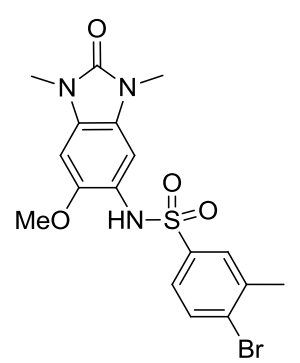

OF-1, (22)

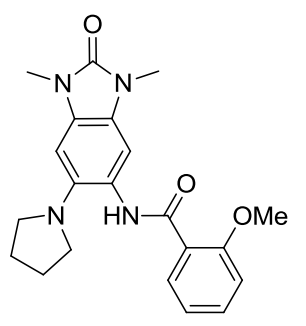

PFI-4, (24) BRPF1B BRPF1B/2/3

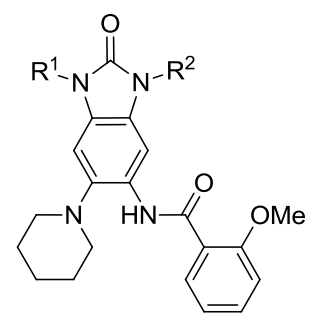
23a, BRPF1B

$\mathrm{R}^{1}=\mathrm{H}, \mathrm{R}^{2}=\mathrm{CH}_{3}$,

23b, negative control<smiles>COc1cc(Cl)ccc1S(=O)(=O)Nc1ccc2c(c1)cc(C)c(=O)n2C</smiles>

NI-57, (25)

BRPF1B/2/3
$\mathrm{R}^{1}=\mathrm{CH}_{3}, \mathrm{R}^{2}=\mathrm{CH}_{3}$,

Figure 7. Chemical structures for BRPF family bromodomain inhibitors.

GSK have reported a series of BRPF1B selective inhibitors, which share the same benzimidazolone core as OF-1 (22). ${ }^{[49]}$ Lead compound 23a (Figure 7) was obtained by cross-screening analogues of a fragment hit identified in a BRD4 STD-NMR screen. 23a shows a $I_{50}: 80 \mathrm{nM}$ (TR-FRET) against BRPF1B, with 100 and $>1000$ fold selectivity over BRPF2 and BRPF3, respectively. Given this excellent activity and selectivity profile, broader bromodomain selectivity was assessed by means of BROMOscan. ${ }^{[33]}$ In a panel of 35 phylogenetically diverse bromodomains, 23a showed a BRPF1B $K_{d}: 7.9 \mathrm{nM}$, with 600 fold selectivity over the BET family. Critically, evidence of cellular target engagement was achieved using a cellular chromatin displacement assay in which 23a showed disruption of chromatin with a $\mathrm{IC}_{50}: 1 \mu \mathrm{M}$. Importantly, this group report compound 23b as a structurally analogous negative control, which will facilitate biological investigations. Of particular note is that compound 23a is the first bromodomain inhibitor reported to be selective for a single bromodomain.

PFI-4 (24) is another benzimidazolone compound reported as a selective inhibitor of BRPF1B. ${ }^{[50]}$ Developed by the SGC in collaboration with Pfizer, PFI-4 (24) binds to selectively BRPF1B with $\mathrm{K}_{\mathrm{d}}$ : $13 \mathrm{nM}$, as determined by ITC. Further details surrounding the development and broader selectivity profile of this compound have not yet been reported.

NI-57 (25) is a BRPF family selective chemical probe developed by the SGC in collaboration with University College
London. ${ }^{[51]}$ As reported on the SGC website, NI-57 (25) binds to BRPF1B ( $\left.\mathrm{K}_{\mathrm{d}}: 31 \mathrm{nM}\right)$, BRPF2 $\left(\mathrm{K}_{\mathrm{d}}: 108 \mathrm{nM}\right)$ and BRPF3 $\left(\mathrm{K}_{\mathrm{d}}\right.$ : $408 \mathrm{nM}$ ), with nanomolar affinity, as determined by ITC. NI-57 (25) is very selective against the BET family and the closest offtarget effects are against BRD9 (32 fold selective).

The number of chemical probes for the BRPF family emerging in the literature will allow significant advances towards target validation of non-BET bromodomains. However, the majority of chemical probes for which the structures have been reported share the same benzimidazolone core. In the future, biological validation experiments would benefit from BRPF1 family chemical probes from a variety of structural scaffolds.

\subsection{CREBBP}

Outside of the BET family, much of the focus in chemical probe discovery has been with the structurally related bromodomains of CREBBP and EP300. This is most likely due to the fact that many unselective BET bromodomain binders also interact with the bromodomain of CREBBP, potentially indicating the high homology between these domains. Nevertheless, these unselective BET inhibitors have served as encouraging start points for the development of some selective CREBBP/EP300 inhibitors.

Research conducted by Zhou and co-workers led to the discovery that the CREBBP bromodomain binds to KAc382 of the human tumour suppressor, p53. ${ }^{[52]}$ It is reported that this specific interaction is required for acetylation dependent coactivator recruitment after DNA damage. In order to develop small molecule binders of the CREBBP bromodomain, Zhou and coworkers aimed to inhibit the CREBBP-p53 interaction, initially reporting compounds MS2126 (26) and MS7972 (27) (Figure 8). ${ }^{[53]}$

These small molecules were discovered by an NMR screen of a focused library of 200 compounds, which was constructed based on the structural knowledge of the CREBBP bromodomain-p53KAc382 3-component interaction. Special attention was paid to the KAc mimetic and electrostatics at the opening of the KAc binding channel, in order to drive selectivity over other bromodomains. As CREBBP is positively charged in this region, electron rich functional groups were included in the compound collection. Of the 200 compounds screened, 14 were identified to bind to the CREBBP bromodomain. Compounds MS2126 (26) and MS7972 (27) were found to block the CREBBP-p53 interaction at concentrations of 100 and $50 \mu \mathrm{M}$, respectively. Furthermore, when tested in U2OS cells with doxorubicinstimulated DNA damage, 26 and 27 suppressed p53 levels, further strengthening the link between CREBBP bromodomain and p53 binding. These results demonstrate that small molecules can modulate $\mathrm{p} 53$ stability and function in response to DNA damage. MS7972 (27) showed a $\mathrm{K}_{\mathrm{d}}$ : $20 \mu \mathrm{M}$ against CREBBP, as determined by a fluorescence anisotropy (FA) assay. 
<smiles>CC(=O)N1c2ccccc2CCC1C</smiles>

MS2126 (26) CREBBP

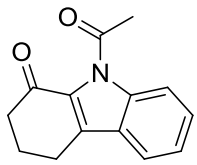

MS7972 (27) CREBBP

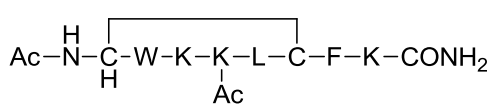

28

$$
\text { CREBBP }
$$<smiles>Cc1cc(N=Nc2cc(S(=O)(=O)O)c(C)cc2C)c(N)cc1O</smiles>

Ischemin (29) CREBBP/EP300<smiles>CCOc1cc(C(=O)O)cc(-c2c(C)noc2C)c1</smiles>

31 CREBBP/BRD4<smiles>COc1ccc2c(c1)N(C)CCC2</smiles>

33

CREBBP/EP300<smiles>CCC(=O)N1CCOc2c(cc(-c3ccc(OC)c(OC)c3)cc2OC[C@@H]2CCCN(C)C2)C1</smiles>

I-CBP112 (30) CREBBP/EP300<smiles>COc1ccc(CCc2nc3cc(-c4c(C)noc4C)ccc3n2C[C@@H](C)N2CCOCC2)cc1Cl</smiles>

SGC-CBP30 (32) CREBBP/EP300
Figure 8. Chemical structures for CREBBP bromodomain inhibitors.

The same group has also reported conformationally restricted cyclic peptides as inhibitors of the CREBBP bromodomain. ${ }^{[54]}$ Through rational design using molecular dynamics simulations on the NMR structure of the CREBBP bromodomain in complex with KAc382 of p53, a series of cyclic peptide inhibitors were identified. These molecules were found to bind to the bromodomain of CREBBP, with greater affinity than natural ligands including p53. Compound $\mathbf{2 8}$ was selected as the lead peptide, which shows a $\mathrm{K}_{d}: 8 \mu \mathrm{M}$ (FP assay), representing a 24 fold improvement in affinity compared to the endogenous ligand. The selectivity of this peptide for CREBBP was confirmed by an FP assay, with no interaction observed for the bromodomains of PCAF and BRD4(1)/(2). Cell-based assays carried out in colorectal carcinoma HCT116 cells demonstrated the efficacy of $\mathbf{2 8}$ to modulate p53 stability and function in response to DNA damage.

Subsequently, Zhou co-workers conducted an NMR screen of a diverse library of 3000 compounds, leading to the identification of the azobenzene moiety as a CREBBP bromodomain ligand. ${ }^{[55]}$ Of the 3000 compounds tested, 10 hits were generated and optimized to deliver Ischemin (29). This molecule inhibits the CREBBP bromodomain-p53 interaction with an $\mathrm{IC}_{50}: 5 \mu \mathrm{M}$, as determined by a cell-based assay. Selectivity over other bromodomains was investigated using a fluorescence displacement assay in which Ischemin (29) was up to 5-fold selective over the bromodomains of PCAF, BRD4(1) and BAZ2B. In cellular assays, Ischemin (29) alters PTMs of p53 and histones, and inhibits the CREBBP-p53 interaction and transcriptional activity. 29 prevents apoptosis in ischemic cardiomyocytes, suggesting that inhibition of the CREBBP bromodomain or the other targets that bind to this compound with similar affinity may provide an effective treatment for diseases such as myocardial ischemia.

These compounds demonstrate the utility of CREBBP bromodomain inhibitors for target validation and their potential to treat human disorders. Since these discoveries, there has been significant interest in the development of alternative CREBBP/EP300 inhibitors.

I-CBP112 (30) is a chemical probe for the bromodomains of CREBBP and EP300, developed by GSK in collaboration with the SGC (Figure 8) ${ }^{[56]}$ I-CBP112 (30) shows $\mathrm{K}_{\mathrm{d}}$ : 151 and $625 \mathrm{nM}$ against CREBBP and EP300, respectively (ITC). Selectivity over a range of bromodomains was established including ATAD2, BAZ2B, BRD2(2), BRD4(1), PB1(5), PCAF, PHIP(2) and TRIM24, as determined by BLI. Further ITC titrations confirmed good selectivity over the BET family ( 37 and 132 fold for BRD4 $\mathrm{BD} 1$ and BD2 respectively). I-CBP112 (30) has been used to probe the biological function of CREBBP/EP300. In leukemia, ICBP112 (30) was found to impair the disease initiating selfrenewal leukemic cells in vitro and in vivo without causing significant toxicity. These studies further validate the role of CREBBP/EP300 in oncology and could potentially pave the way for future therapies.

The 3,5-dimethylisoxazole fragment is a well-studied KAc mimetic, which features in a number of BET bromodomain inhibitors (see $\mathbf{3}$ and 5, Figure 3). However, some of these compounds show some activity against the CREBBP bromodomain, with compound $\mathbf{3 1}$ displaying an $\mathrm{IC}_{50}$ value of $32 \mu \mathrm{M}$, as determined by AlphaScreen. ${ }^{[20]}$ Although not selective over the BET family [BRD4(1) IC $\mathrm{C}_{50}: 51 \mu \mathrm{M}$; BRD2(1) IC $\mathrm{C}_{50}: 28 \mu \mathrm{M}$ ], compound $\mathbf{3 1}$ could be considered as a good start point for the development of more potent and selective ligands for CREBBP. Towards this goal, the SGC collaborated with the University of Oxford to deliver SGC-CBP30 (32). ${ }^{[57]}$ SGC-CBP30 (32) shows $\mathrm{K}_{\mathrm{d}}: 21$ and $38 \mathrm{nM}$ against CREBBP and EP300, respectively, as determined by ITC. In addition, compound $\mathbf{3 2}$ is 40 fold selective 
over BET family member, BRD4(1). Broader bromodomain selectivity was assessed by thermal shift, in which compound $\mathbf{3 2}$ was tested against 10 targets. No $\Delta T_{m}$ above $2{ }^{\circ} \mathrm{C}$ was observed against any other bromodomains apart from BET family members BRD2(1), BRD3(1), and BRD4(1), with $\Delta T_{m}$ between 1 and $2{ }^{\circ} \mathrm{C}$. Cellular target engagement was determined using a FRAP assay, in which $\mathbf{3 2}$ was shown to disrupt CREBBP bromodomain-chromatin complex in HeLa cells. To investigate the effect of compound $\mathbf{3 2}$ on the CREBBP bromodomain-p53 interaction in a cellular context, a luciferase reporter assay for p53 induction was used. Compound 32 inhibited doxorubicin induced p53 activity with an $\mathrm{IC}_{50}: 1.5 \mu \mathrm{M}$. ADME properties were determined for $\mathbf{3 2}$ in order to understand it's utility as an in vivo probe. In a human liver microsome stability assay, no compound was detected after 1 hour, suggesting rapid metabolism. Although $\mathbf{3 2}$ may not be suitable as an in vivo tool, this compound is likely to be valuable in understanding the biological function of both CREBBP and EP300 in vitro.

Conway and coworkers reported compound $\mathbf{3 3}$ as a ligand for the CREBBP bromodomain. ${ }^{[58]} 33$ displays a $K_{d}$ : $390 \mathrm{nM}$ against CREBBP (ITC), with modest selectivity over BRD4(1) $\left(\mathrm{K}_{\mathrm{d}}: 1.4 \mu \mathrm{M}\right)$. A FRAP assay was used to evaluate 33 in a cellular setting. Compound $\mathbf{3 3}$ was found to displace the CREBBP bromodomain from chromatin in U2OS cells in a dose dependent manner. Although not selective over the BET family, 33 is a valuable addition to the CREBBP tool set to help validate this protein as a target for the treament of disease.

Most recently, Unzue and co-workers report the development of compound $\mathbf{3 4}$ as an inhibitor of CREBBP. ${ }^{[59]}$ Ligand identification was conducted by fragment-based docking into the structure of the CREBBP bromodomain. Of the 17 compounds initially selected for in vito validation, the acetyl benzene scaffold was selected for further investigation to deliver a series of CREBBP inhibitors. Compound $\mathbf{3 4}$ showed the best combination of potency and selectivity with a CREBBP $\mathrm{K}_{\mathrm{d}}$ : $2.0 \mu \mathrm{M}$ and BRD4(1) $\mathrm{K}_{\mathrm{d}}:>50 \mu \mathrm{M}$, as determined by ITC.

The efforts towards chemical probe discovery for the bromodomains of CREBBP/EP300 have proved extremely useful to enable target validation within human disease. Importantly, these discoveries have provided a range of structurally distinct inhibitors, which address potential off target binding and build further confidence in the biological phenotypes observed.

\subsection{PCAF}

Zhou and co-workers were the first to report a small molecule ligand for a bromodomain, namely PCAF. This group showed that the bromodomain of PCAF binds specifically to KAc50 of the HIV-Tat protein complex, a critical interaction for viral replication. ${ }^{[60]}$ Moving forward, NMR screening was used to discover small molecule inhibitors of this interaction. These efforts led to the discovery of several inhibitors including compound 35, which displays $\mathrm{IC}_{50}: 1.6 \mu \mathrm{M}$ against PCAF, as determined by a peptide competition assay (Figure 9). Despite efforts to optimise compound $\mathbf{3 5}$, no increase in potency was reported. ${ }^{[61]}$<smiles>Cc1ccc(NCCCN)c([N+](=O)[O-])c1</smiles>

35

PCAF

Figure 9. Chemical structure of PCAF inhibitor 35.

\subsection{SMARCA4}

SMARCA4 is part of the SNF/SWI complex, which plays a key role in chromatin remodelling and transcription control. Loss of function of SMARCA4 and components of SWI/SNF has been linked to cancer development. ${ }^{[62]}$ Pfizer and the SGC have collaborated to develop PFI-3 (36), an inhibitor for the bromodomain of SMARCA4 (Figure 10). ${ }^{[63]}$ This novel chemotype demonstrates $\mathrm{K}_{\mathrm{d}}: 89 \mathrm{nM}$ against SMARCA4, as well as $48 \mathrm{nM}$ against the homologous PB1(5) bromodomain (ITC). Broader bromodomain selectivity was assessed by thermal shift with binding confirmed at SMARCA4 $\left(\Delta \mathrm{T}_{\mathrm{m}}: 5.1\right)$, SMARCA2 $\left(\Delta T_{m}: 6.4\right)$ and PB1(5) $\left(\Delta T_{m}: 7.5\right)$. No interaction was observed with PB1(2-4), and there was no cross-reactivity in a panel of 36 kinases.

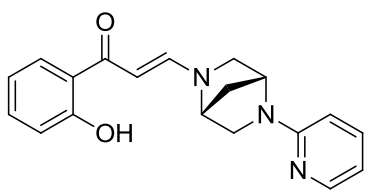

$\mathrm{PFI}-3$ (36)

SMARCA2/4, PB1(5)

Figure 10. Chemical structure for SMARCA2/4, PB1(5) inhibitor, PFI-3 (36). ${ }^{[64]}$

Interestingly, PFI-3 (36) has been used to probe the biological function of the SMARCA2/4 bromodomains. Although PFI-3 (36) is capable of displacing the SMARCA2 bromodomain from chromatin, demonstrating cellular target engagement, it fails to show the antiproliferative phenotype observed through SiRNA knock-down studies. Therefore, PFI-3 (36) has invalidated the SMARCA2 bromodomain, and instead, helped to identify the ATPase domain as the relevant therapeutic target. These studies further highlight the power of chemical probes for both target validation and in validation, particularly in combination with protein knock-down experiments.

\subsection{OTHERS}

There are a growing number of bromodomain inhibitors that are broadly selective, showing activity against a small number of bromodomains. Examples include compound 33, which shows activity against TAF1(2), TAF1L(2) and BRD4 (Figure 11). ${ }^{[65]}$ Bradner and coworkers used fluorous tagged multicomponent reactions to develop a library of 3,5dimethylisoxazole containing bromodomain inhibitors. Subsequent optimization of the scaffold delivered lead compound 37, which binds to BRD4(1) with a $\mathrm{K}_{\mathrm{d}}$ : $550 \mathrm{nM}$ as determined by ITC. Broader bromodomain screening by means 
of BROMOscan ${ }^{[33]}$ confirmed binding to BRD4 ( $\left.\mathrm{K}_{\mathrm{d}}: 80 \mathrm{nM}\right)$ but revealed potent binding to TAF1(2) ( $\left.\mathrm{K}_{\mathrm{d}}: 560 \mathrm{nM}\right)$ and TAF1L(2) $\left(\mathrm{K}_{\mathrm{d}}: 1.3 \mu \mathrm{M}\right)$. Although the binding to $\mathrm{TAF} 1(2)$ is relatively weak, this observation suggests a starting point for the development of a selective TAF1 bromodomain chemical probe.

The SGC have reported benzimidazolone $\mathbf{3 8}$ as an inhibitor of BRPF1B/2 and TRIM24. ${ }^{[66]}$ In order to develop a TRIM24 specific inhibitor, commercially available 1,3benzimidazolones were screened using AlphaScreen technology Several compounds were identified to be active against TRIM24 but were also active against BRPF1B/2. Moving forward, the 5 and 6-positions of the template were optimised to deliver compound 38, which shows a $\mathrm{K}_{\mathrm{d}}$ : $222 \mathrm{nM}$ and $137 \mathrm{nM}$ against TRIM24 and BRPF1B respectively (ITC). The selectivity of compound 38 was evaluated using a thermal shift assay consisting of a panel of 45 bromodomains. Significant shifts were observed for BRPF1B/2 and TRIM24, supporting the ITC data generated. Cellular activity was determined using a FRAP assay in which $\mathbf{3 8}$ displaced full-length TRIM24 from chromatin.<smiles>Cc1noc(C)c1-c1ccc(C2=C(NC(C)C)N3C=CN=CC3N2)cc1</smiles>

37

TAF1(2), TAF1L(2), BRD4<smiles>COc1ccc(Oc2cc3c(cc2NS(=O)(=O)c2ccc(OC)c(OC)c2)n(C)c(=O)n3C)cc1</smiles>

BRPF1B/2, TRIM24

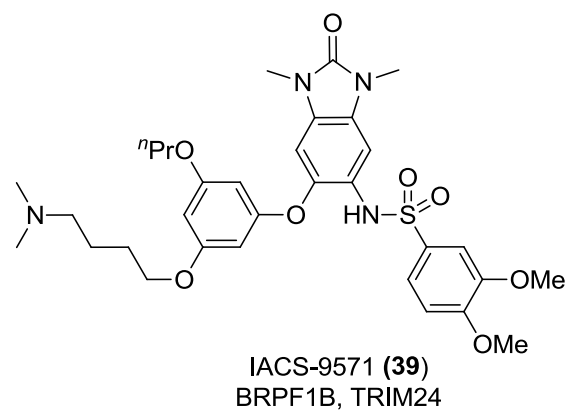

Figure 11. Chemical structures for bromodomain inhibitors 37,38 and 39 .

Independently, Palmer and co-workers used a structure guided approach to develop compound 39 as a TRIM24 inhibitor. ${ }^{[67]}$ In order to develop a selective TRIM24 inhibitor, three hit identification approaches were explored: virtual in silico high-throughput screening (HTS), construction of a focused KAc mimetic library, and a traditional small molecule HTS. Three different chemotypes were indentified, with the same benzimidazolone template as compound $\mathbf{3 8}$ selected for further optimisation. SAR evaluation around this core provided IACS9571 (39), which is potent against the bromodomain of TRIM24 [IC $\mathrm{I}_{50}: 7.6 \mathrm{nM}$, (AlphaScreen)]. Broader selectivity profiling was asessed by BROMOscan ${ }^{[3]}$ in which 39 was tested against 32 bromodomains. Results from this screen indicated off activity against the BRPF family. Subsequent dose-response determinations demonstrated $\mathbf{3 9}$ to be a dual TRIM24/BRPF1B inhibitor ( $\left.\mathrm{K}_{\mathrm{d}}: 1.3 / 2.1 \mathrm{nM}\right)$, with 9 and 21 fold selectivity over BRPF2 and BRPF3 respectively. Compound 39 does not interact with the bromodomains of the BET family, displaying greater than 7700 fold selectivity versus BRD4(1/2) relative to TRIM24. Pharmacokinetic parameters were determined for 39 in female CD1 mice after IV administartion of a $1 \mathrm{mg} / \mathrm{kg}$ dose. Moderate clearence $(43 \mathrm{~mL} / \mathrm{min} / \mathrm{kg})$ was observed and the terminal half life was $0.7 \mathrm{~h}$. After oral dosing of $10 \mathrm{mg} / \mathrm{kg}$, bioavailability of $\mathbf{3 9}$ was $29 \%$, suggesting that this molecule could be used for in vivo studies.

Although selectivity over the BRPF family could not be achieved for both $\mathbf{3 8}$ and $\mathbf{3 9}$, these compounds might represent a good starting point towards the development of a selective TRIM24 inhibitor, which could serve as a valuable tool for understanding the biology of this bromodomain.

\subsection{Outlook}

The development of chemical probes for bromodomains represents an exciting area of research for both academic and industrial laboratories. Although much of the research has focused on the BET family, there have been significant advances outside of this subgroup. The identification of promising start points and in some cases potent and selective chemical probes by both academic and industrial laboratories has facilitated rapid progression in this field. Importantly, the majority of these probe molecules have been made available to the scientific community in an effort to elucidate the biological function of human bromodomains. In particular, the pioneering efforts of the SGC and their collaborators have led the way for both BET and non-BET chemical probe research programmes.

There are now validated chemical probes or potential start points towards chemical probes for several of the main bromodomain families of the human phylogenetic tree. This represents a significant advancement in the field, allowing an understanding of the biology for a structurally diverse set of bromodomains. In the majority of cases, these chemical probes are selective for a particular branch of the phylogenetic tree, targeting at least two bromodomains. It is unknown whether multi-bromodomain pharmacology is necessary to observe a biological phenotype or if more selective bromodomain inhibition is required. Interestingly, multi-bromodomain activity is not always observed within the same family. During our own experience developing I-BRD9 (19) we observed binding to the bromodomain of CECR2 with next greatest affinity after BRD9, not BRD7 as expected. Therefore, small molecule off-target 
activities are not always predictable based on the sequence homology of the phylogenetic tree.

Of the non-BET chemical probes discussed in this review, only GSK2801 (15a), BAZ-ICR (16) and IACS-9571 (39) are reported to be suitable for use as in vivo tools. It is not clear whether the other inhibitors reported would be suitable for in vivo experiments, which may highlight a limitation in the discoveries made to date. Therefore, future effort should be placed on the development of in vivo tools so that the community can fully understand the role of bromodomains in preclinical models, to provide further insight into their potential therapeutic utility in human disease. However, it is important to note that despite extensive effort, inhibition of non-BET bromodomains by chemical probes has yet to deliver a clear disease phenotype in the majority of cases. This perhaps highlights that the discovery of high quality chemical probes is only the first step on a difficult path towards a new class of therapeutics.

Due to the importance of chemical probes for enabling target validation, it is critical that confidence in any phenotype observed is due to inhibition of the target protein. As such, the selectivity criteria for a chemical probe is arguably more demanding than that of a drug candidate. ${ }^{[7]}$ However, it is always possible, and indeed likely that any chemical probe will possess off target activity. Therefore, we advocate the use of structurally similar negative control compounds as well as structurally distinct chemical probes to enable cross validation studies. ${ }^{[68]}$ It is pleasing to see non-BET bromodomain chemical probes along with their biologically negative analogues emerging in the literature.

There are a growing number of bromodomains for which there are multiple chemical probes from a diverse range of chemotypes. Examples include CREBBP, BAZ2A/B and BRD9, highlighting their tractability to small molecule binding. As a result, the epigenetic community is now in a better position than ever to fully investigate the therapeutic potential of these targets. In particular, the chemical probes developed for BAZ2A/B represent an excellent toolset to investigate the biology, which will facilitate validation of these bromodomains. These probes are in vivo capable, structurally orthogonal and there is a structurally similar negative control compound available. We believe that future work in this field should focus on the development of chemical probe toolsets, which fulfill these criteria. ${ }^{[7]}$ This, in turn, will provide a better understanding of the human bromodomain family and may aid investigations into the role of broader epigenetic processes within human disease.

\section{Acknowledgements}

N.H.T. is grateful to GlaxoSmithKline R\&D, Stevenage for Ph.D. studentship funding. We appreciate helpful discussions with Emmanuel Demont and Paul Bamborough during the course of this work. We thank Paul Bamborough for creating both Figure 2 and the table of contents graphic.

Keywords: bromodomain $\cdot$ non-BET $\bullet$ chemical probe $\bullet$ inhibitor - epigenetics
[1] C. H. Arrowsmith; C. Bountra, P. V. Fish, K. Lee, M. Schapira, Nat. Rev. Drug Discovery 2012, 11, 384-400.

[2] R. Sanchez, M. M. Zhou, Curr. Opin. Drug Discovery Dev. 2009, 12, 659-665.

[3] C. W. Chung, D. F. Tough, Drug Discov. Today: Ther. Strategies 2012 9, 111-120

[4] C. W. Chung, Prog. Med. Chem. 2012, 51, 1-55.

[5] S. Mujtaba, L. Zeng, M. M. Zhou, Oncogene 2007, 26, 5521-5527.

[6] A. F. Hohmann, C. R. Vakoc, Trends in Genetics 2014, 30, 356-363.

[7] M. E. Bunnage, E. L. Piatnitski Chekler, L. H. Jones, Nat. Chem. Biol. 2013, 9, 195-199.

[8] S. Müller, P. J. Brown, Clin. Pharmacol. Ther. 2012, 92, 689-693.

[9] P. Filippakopoulos, S. Knapp, FEBS Lett. 2012, 586, 2682-2704.

[10] P. Filippakopoulos, S. Picaud, M. Mangos, T. Keates, J. P. Lambert, D. Barsyte-Lovejoy, I. Felletar, R. Volkmer, S. Müller, T. Pawson, A. C. Gingras, C. H. Arrowsmith, S. Knapp, Cell 2012, 149, 214-231.

[11] E. Nicodeme, K. L. Jeffrey, U. Schaefer, S. Beinke, S. Dewell, C. W. Chung, R. Chandwani, I. Marazzi, P. Wilson, H. Coste. J. White, J. Kirilovsky, C. M. Rice, J. M. Lora, R. K. Prinjha, K. Lee, A. A. Tarakovsky, Nature 2010, 468, 1119-1123.

[12] O. Mirguet, R. Gosmini, J. Toum, C. A. Clement, M. Barnathan, J. M. Brusq, Mordaunt, J. E.; R. M. Grimes, M. Crowe, O. Pineau, M. Ajakane, A. Daugan, P. Jeffrey, L. Cutler, A. C. Haynes, N. N. Smithers; C. W. Chung, P. Bamborough, I. J. Uings, A. Lewis, J. Witherington, N. Parr, R. K. Prinjha, E. Nicodeme, J. Med. Chem. 2013, 56, 7501-7515.

[13] C. W. Chung, H. Coste, J. H. White, O. Mirguet, J. Wilde, R. L. Gosmini, C. Delves, S. M. Magny, R. Woodward, S. A. Hughes, E. V. Boursier, H. Flynn, A. M. Bouillot, P. Bamborough, J. M. G. Brusq, F. J. Gellibert, E. J. Jones, A. M. Riou, P. Homes, S. L. Martin, I. J. Uings, J. Toum, C. A. Clement, A. B. Boullay, R. L. Grimley, F. M. Blandel, R. K. Prinjha, K. Lee, J. Kirilovsky, E. Nicodeme, J. Med. Chem. 2011, 54, 3827-3838.

[14] P. Filippalopoulos, J. Qi, S. Picaud, Y. Shen, W. B. Smith, O. Fedorov, E. M. Morse, T. Keates, T. T. Hickman, I. Felletar, M. Philpott, S. Munro, M. R. McKeown, Y. Wang, A. L. Christie, N. West, M. J. Cameron, B. Schwartz, T. D. Heightman, N. La Thangue, C. A. French, O. Wiest, A L. Kung, S. Knapp, J. E. Bradner, Nature 2010, 468, 1067-1073.

[15] S. Miyoshi, S. Ooike, K. Iwata, H. Hikawa, K. Sugahara, Int. Pat. Appl. WO 2009/084693, 2009.

[16] M. A. Dawson, R. K. Prinjha, A. Dittmann, G. Giotopoulos, M. Bantscheff, W. I. Chan, S. Robertson, C. W. Chung, C. Hopf, M. M. Savitski, C. Huthmacher, E. Gudgin, D. Lugo, S. Beinke, T. D. Chapman, E. J. Roberts, P. E. Soden, K. R. Auger, O. Mirguet, K. Doehner, R. Delwel, A. K. Burnett, P. Jeffrey, G. Drewes, K. Lee, B. J. P. Huntly, T. Kouzarides. Nature 2011, 478, 529-533.

[17] O. Mirguet, Y. Lamotte, F. Donche, J. Toum, F. Gellibert, A. Bouillot, R. Gosmini, V. L. Nguyen, D. Delannee, J. Seal, F. Blandel, A. B. Boullay, E. Boursier, S. Martin, J. M. Brusq, G. Krysa, A. Riou, R. Tellier, A. Costaz, P. Huet, Y. Dudit, L. Trottet, J. Kirilovsky, E. Nicodeme, Bioorg. Med. Chem. Lett. 2012, 22, 2963-2967.

[18] J. Seal, Y. Lamotte, F. Donche, A. Bouillot, O. Mirguet, F. Gellibert, E. Nicodeme, G. Krysa, J. Kirilovsky, S. Beinke, S. McCleary, I. Rioja, P. Bamborough, C. W. Chung, L. Gordon, T. Lewis, A. L. Walker, L. Cutler, D. Lugo, D. M. Wilson, J. Witherington, K. Lee, R. K. Prinjha, Bioorg Med. Chem. Lett. 2012, 22, 2968-2972.

[19] P. V. Fish, P. Filippakopoulos, G. Bish, P. E. Brennan, M. E. Bunnage, A. S. Cook, O. Fedorov, B. S. Gerstenberger, H. Jones, S. Knapp, B Marsden, K. Nocka, D. R. Owen, M. Philpott, S. Picaud, M. J. Primiano, M. J. Ralph, N. Sciammetta, J. D. Trzupek, J. Med. Chem. 2012, 55, 9831-9837.

[20] D. S. Hewings, M. Wang, M. Philpott, O. Fedorov, S. Uttarkar, P Filippakopoulos, S. Picaud, C. Vuppusetty, B. Marsden, S. Knapp, S. J. Conway, T. D. Heightman, J. Med. Chem. 2011, 54, 6761-6770.

[21] D. S. Hewings, O. Fedorov, P. Filippakopoulos, S. Martin, S. Picaud, A. Tumber, C. Wells, M. M. Olcina, K. Freeman, A. Gill, A. J. Ritchie, D. W. 
Sheppard, A. J. Russell, E. M. Hammond, S. Knapp, P. E. Brennan, S. J. Conway, J. Med. Chem. 2013, 56, 3217-3227.

[22] G. Zhang, A. N. Plotnikov, E. Rusinova, T. Shen, K. Morohasshi, J. Joshua, L. Zeng, S. Mujtaba, M. Ohlmeyer, M. M. Zhou, J. Med. Chem. 2013, 56, 9251-9264.

[23] K. G. McLure, E. M. Gesner, L. Tsujikawa, O. A. Kharenko, S. Attwell, E. Campeau, S. Wasiak, A. Stein, A. White, E. Fontano, R. K. Suto, N C. Wong, G. S. Wagner, H. C. Hansen, P. R. Young, PLoS. One. 2013 8, e83190.

[24] For recent reviews of BET bromodomain inhibitors and their therapeutic potential see: (a) D. S. Hewings, T. P. C. Rooney, L. E. Jennings, D. A. Hay, C. J. Schofield, P. E. Brennan, S. Knapp, S. J. Conway, J. Med. Chem. 2012, 55, 9393-9413; (b) S. Furdas, L. Carlino, W. Sippl, M. Jung, MedChemComm. 2012, 3, 123-134; (c) R. K. Prinjha, J. Witherington, K. Lee, Trends Pharmacol. Sci. 2012, 33, 146-153; (d) S. Knapp, H. Weinmann, ChemMedChem 2013, 3, 1885-1891; (e) R. F. Sweis. M. R. Michaelides, Annu. Rep. Med. Chem. 2013, 48, 185-199; (f) L. E. Jennings, A. R. Measures, B. G. Wilson, S. J. Conway, Future Med. Chem. 2014, 6, 179-204; (g) J. M. Garnier, P. P. Sharp, C. J. Burns, Expert Opin. Ther. Patents 2014, 24, 185-199; (h) M. Brand; A. M. Measures; B. G. Wilson; W. A. Cortopassi; R. Alexander; M. Hoss; D. S. Hewings; T. P. C. Rooney; R. S. Paton; S. J. Conway, ACS Chem Biol. 2015, 10, 22-39.

[25] Bromosporine: http://www.thesgc.org/chemical-probes/bromosporine (accessed 16/11/2015).

[26] O. Fedorov, H. Lingard, C. Wells, O. P. Monteiro, S. Picaud, T. Keates, C. Yapp, M. Philpott, S. J. Martin, M. I. Felletar, B. Marsden, P. Filippakopoulos, S. Müller, S. Knapp, P. E. Brennan, J. Med. Chem. 2014, 57, 462-476.

[27] C. Caron, C. Lestrat, S. Marsal, E. Escoffier, S. Curtet, V. Virolle, P. Barbry, A. Debernardi, C. Brambilla, E. Brambilla, S. Rousseaux, S. Khochbin, Oncogene, 2010, 29, 5171-5181.

[28] L. R. Vidler, N. Brown, S. Knapp, S. Hoelder, J. Med. Chem. 2012, 55, 7346-7359.

[29] M. J. Harner, B. A. Chauder, J. Phan, S. W. Fesik, J. Med. Chem. 2014 57, 9687-9692.

[30] A. Chaikuad; A. M. Petros; O. Fedorov; J. Xu; S. Knapp, MedChemComm. 2014, 5, 1843-1848.

[31] E. H. Demont, C. W. Chung, R. C. Furze, P. Grandi, A. M. Michon, C. Wellaway, N. Barrett, A. M. Bridges, P. D. Craggs, H. Diallo, D. P. Dixon, C. Douault, A. J. Emmons, E. J. Jones, B. V. Karamshi, K. Locke, D. J. Mitchell, B. H. Mouzon, R. K. Prinjha, A. D. Roberts, R. J. Sheppard, R. J. Watson, P. Bamborough, J. Med. Chem. 2015, 58, 5649-5673.

[32] P. Bamborough, C. W. Chung, R. C. Furze, P. Grandi, A. M. Michon, R. J. Sheppard, H. Barnett, H. Diallo, D. P. Dixon, C. Douault, E. J. Jones, B. V. Karamshi, D. J. Mitchell, R. K. Prinjha, C. Rau, R. J. Sheppard, R. J. Watson, T. Werner, E. H. Demont, J. Med. Chem. 2015, 58, 61516178.

[33] BROMOscan: http://www.discoverx.com/services/drug-discoverydevelopment-services/epigenetic-profiling/bromoscan (accessed 16/11/2015).

[34] F. M. Ferguson, O. Fedorov, A. Chaikaud, M. Philpott, J. R. C. Muniz, I. Felletar, F. von Delft, T. Heightman, S. Knapp, C. Abell, A. Ciulli, J. Med. Chem. 2013, 56, 10183-10187.

[35] P. Chen, A. Chaikuad, P. Bamborough, M. Bantscheff, C. Bountra, C. W. Chung, O. Fedorov, P. Grandi, D. Jung, R. Lesniak, M. Lindon, S. Müller, M. Philpott, R. Prinjha, C. Rogers, C. Selenski, C. Tallant, T. Werner, T. M. Willson, S. Knapp, D. H. Drewry, J. Med. Chem. 2015, DOI: 10.1021/acs.jmedchem.5b00209.

[36] C. W. Chung, A. W. Dean, J. M. Woolven, P. Bamborough, J. Med. Chem. 2012, 55, 576-586.

[37] L. Drouin, S. McGrath, L. R. Vidler, A. Chaikuad, O. Monteiro, C. Tallant, M. Philpott, C. Rogers, O. Fedorov, M. Liu, W. Akhtar, A. Hayes,
F. Raynaud, S. Müller, S. Knapp, S. Hoelder, J. Med. Chem. 2015, 5 2553-2559.

[38] L. Guetzoyan, R. J. Ingham, N. Nikbin, J. Rossignol, M. Wolling, M Baumert, N. A. Burgess-Brown, C. M. Strain-Damerell, L. Shrestha, P. E. Brennan, O. Fedorov, S. Knapp, S. V. Ley, MedChemComm. 2014, 5, 540-546

[39] S. Picaud; M. Strocchia; S. Terracciano; G. Lauro; J. Mendez; D. L. Daniels; R. Ricco; G. Bifulco; I. Bruno; P. Fillipakopoulos, J. Med Chem. 2015, 58, 2718-2736.

[40] T. Machleidt, C. C. Woodroofe, M. K. Schwinn, J. Méndez, M. B. Robers, K. Zimmerman, P. Otto, D. L. Daniels, T. A. Kirkland K. V Wood, ACS Chem. Biol. 2015, 10, 1797-1804.

[41] N. H. Theodoulou, P. Bamborough, A. J. Bannister, I. Becher, R. A. Bit K. H. Che, C. W. Chung, A. Dittmann, G. Drewes, D. H. Drewry, L. Gordon, .P Grandi, M. Leveridge, M. Lindon, A. M. Michon, J. Molnar, S. C. Robson, N. C. O. Tomkinson, T. Kouzarides, R. K. Prinjha, P. G. Humphreys' J. Med. Chem. 2015 DOI: 10.1021/acs.jmedchem.5b00256.

[42] T. Werner, I. Becher, G. Sweetman, C. Doce, M. M. Savitski, M. Bantscheff, Anal. Chem. 2012, 84, 7188-7194.

[43] M. Bantscheff, D. Eberhard, Y. Abraham, S. Bastuck, M. Boesche, S Hobson, T. Mathieson, J. Perrin, M. Raida, C. Rau, V. Reader, G. Sweetman, A. Bauer, T. Bouwmeester, C. Hopf, U. Kruse, G. Neubauer, N. Ramsden, J. Rick, B. Kuster, G. Drewes, Nat. Biotechnol. 2007, 25, 1035-1044.

[44] P. G. K. Clark, L. C. C. Vieira, C. Tallant, O. Fedorov, D. C. Singleton, C. M. Rogers, O. P. Monteiro, J. M. Bennett, R. Baronio, S. Müller, D. L. Daniels, J. Méndez, S. Knapp, P. E. Brennan, D. J. Dixon, Angew. Chem. 2015, 127, 1-6.

[45] BI-9564: A chemical probe for BRD9 and BRD7 http://www.thesgc.org/chemical-probes/BI-9564 (accessed 18/06/2015).

[46] D. A. Hay, C. M. Rogers, O. Fedorov, C. Tallant, S. Martin, O. P. Monteiro, S. Müller, S. Knapp, C. J. Schofield, P. E. Brennan MedChemComm. 2015, 6, 1381-1386.

[47] M. Ullah, N. Pelletier, L. Xiao, S. P. Zhao, K. Wang, C. Degerny, S. Tahmasebi, C. Cayrou, Y. Doyon, S. L. Goh, N. Champagne, J. Cote, X. J. Yang, Mol. Cell. Biol. 2008, 28, 6828-6843.

[48] OF-1: A chemical probe for BRPF bromodomains. http://www.thesgc.org/chemical-probes/OF-1 (accessed 16/11/2015).

[49] E. H. Demont, P. Bamborough, C. W. Chung, P. D. Craggs, D. Fallon, L. J. Gordon, P. Grandi, C. I. Hobbs, J. Hussain, E. J. Jones, A. Le Gall, A. M. Michon, D. J. Mitchell, R. K. Prinjha, A. D. Roberts, R. J. Sheppard, R. Watson, ACS Med. Chem. Lett. 2014, 11, 1190-1195.

[50] PFI-4: A chemical probe for BRPF1B. http://www.thesgc.org/node/9362 (accessed 16/11/2015).

[51] NI-57: A chemical probe for BRPF bromodomains http://www.thesgc.org/node/9363 (accessed 16/11/2015).

[52] S. Mujtaba, Y. He, L. Zeng, S. Yan, O. Plotnikova, Sachchidanand, R Sanchez, N. J. Zeleznik-Le, Z. Ronai, M. M. Zhou, Mol. Cell 2004, 13, 251-263.

[53] Sachchidanand, L. Resnick-Silverman, S. Yan, S. Mutjaba, W.-J. Liu, L. Zeng, J. J. Manfredi, M. M. Zhou, Chem. Biol. 2006, 13, 81-90.

[54] G. Gerona-Navarro; Y. Rodriguez-Fernandez; S. Mujtaba; J. Patel; L. Zeng; A. N. Plotnikov; R. Osman; M. M. Zhou, J. Am. Chem. Soc. 2011, 133, 2040-2043.

[55] J. C. Borah, S. Mujtaba, I. Karakikes, L. Zeng, M. Muller, J. Patel, N. Moshkina, K. Morohashi, W. Zhang, G. Gerona-Navarro, R. J. Hajjar, M. M. Zhou, Chem. Biol. 2011, 18, 531-541.

[56] S. Picaud, O. Fedorov, A. Thanasopoulou, K. Leonards, K. Jones, J. Meier, H. Olzscha, O. Monteiro, S. Martin, M. Philpott, A. Tumber, P. Filippakopoulos, C. Yapp, C. Wells, K. Hing Che, A. Bannister, S Robson, U. Kumar, N. Parr, K. Lee, D. Lugo, P. Jeffrey, S. Taylor, M. L. Vecellio, C. Bountra, P. Brennan, A. O'Mahony, S. Velichko, S. Muller D. Hay, D. L. Daniels, M. Urh, N. B. La Thangue, T. Kouzarides, R. K. Prinjha, J. Schwaller, S. Knapp, Cancer Res. 2015 doi:10.1158/00085472.CAN-15-0236. 
[57] D. A. Hay, O. Fedorov, S. Martin, D. C. Singleton, C. Tallant, C. Wells, S. Picaud, M. Philpott, O. P. Monteiro, C. M. Rogers, S. J. Conway, T. P. C. Rooney, A. Tumber, C. Yapp, P. Filippakopoulos, M. E. Bunnage, S. Müller, S. Knapp, C. J. Schofield, P. E. Brennan, J. Am. Chem. Soc 2014, 136, 9308-9319.

[58] T. P. C. Rooney, P. Filippakopoulos, O. Fedorov, S. Picaud, W. A Cortopassi, D. A. Hay, S. Martin, A. Tumber, C. M. Rogers, M. Philpott, M. Wang, A. L. Thompson, T. D. Heightman, D. C. Pryde, A. Cook, R S. Paton, S. Müller, S. Knapp, P. E. Brennan, S. J. Conway, Angew. Chem. Int. Ed. 2014, 53, 6126-6130.

[59] A. Unzue, M. Xu, J. Dong, L. Wiedmer, D. Spiliopoulos, A. Caflisch, C. Nevado J. Med. Chem. 2015, DOI:10.1021/acs.jmedchem.5b00172.

[60] S. Mujtaba; Y. He; L. Zeng; A. Farooq; J. E. Carlson; M. Ott; E. Verdin; M. M. Zhou, Mol. Cell 2002, 9, 575-586.

[61] L. Zeng, J. Li, M. Muller, S. Yan, S. Mujtaba, C. Pan, Z. Wang, M. M. Zhou, J. Am. Chem. Soc. 2005, 127, 2376-2377.

[62] P. P. Medina, J. Carretero, M. F. Fraga, M. Esteller, D. Sidransky, M. Sanchez-Cespedes, Gene Chromosome Canc. 2004, 41, 170-177.

[63] B. Vangamudi, T. A. Paul, P. K. Shah, M. Kost-Alimova, L. Nottebaum, X. Shi, Y. Zhan, E. Leo, H. S. Mahadeshwar, A. Protopopov, A. Futreal, T. N. Tieu, M. Peoples, T. P. Heffernan, J. R. Marszalek, C. Toniatti, A. Petrocchi, D. Verhelle, D. R. Owen, G. Draetta, P. Jones, W. S. Palmer, S. Sharma, J. N. Andersen, Cancer Res. 2015, doi: 10.1158/00085472.CAN-14-3798.

[64] Binding mode of PFI-3 (36) not known.

[65] M. R. McKeown, D. L. Shaw, H. Fu, S. Liu, X. Xu, J. J. Marineau, Y. Huang, X. Zhang, D. L. Buckley, A. Kadam, Z. Zhang, S. C. Blacklow, J. Qi, W. Zhang, J. E. Bradner, J. Med. Chem. 2014, 57, 9019-9027.

[66] J. M. Bennett, O. Fedorov, C. Tallant, O. P. Monteiro, J. Meier, V. Gamble, P. Savitski, G. A. Nunez-Alonso, B. Haendler, C. Rogers, P. E. Brennan, S. Müller, S. Knapp, J. Med. Chem. 2015, DOI 10.1021/acs.jmedchem.5b00458.

[67] W. S. Palmer, G. Poncet-Montange, G. Liu, A. Petrocchi, N. Reyna, G. Subramanian, J. Theroff, A. Yau, M. Kost-Alimova, J. P. Bardenhagen, E. Leo, H. E. Shepard, T. N. Tieu, X. Shi, Y. Zhan, S. Zhao. G. Draetta, C. Toniatti, P. Jones, M. G. Do, J. N. Anderson, J. Med. Chem. 2015, DOI: $10.1021 /$ acs.jmedchem.5b00405.

[68] R.F. Sweis, ACS Med. Chem. Lett. 2015, 6, 618-621. 


\section{Entry for the Table of Contents}

Layout 1:

\section{MINIREVIEW}

The development of chemical probes for non-BET bromodomains is a new and rapidly advancing field. Chemical probes for these bromodomains will help to elucidate their biological roles and potentially lead to the development of new medicines. This review summarises the progress made towards this goal and highlights areas for future work.

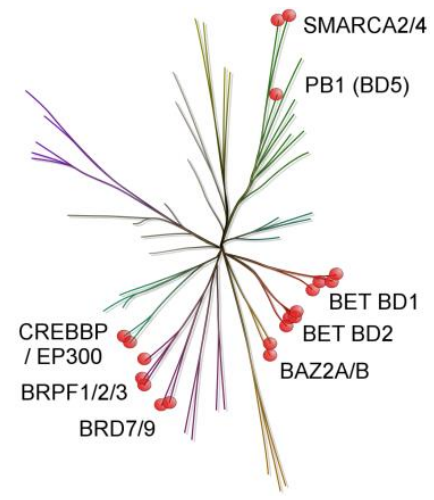

Natalie H. Theodoulou,

Nicholas C. O. Tomkinson,

Rab K. Prinjha and Philip G.

Humphreys*

Page No. - Page No.

Progress in the

Development of non-BET

Bromodomain Chemical

Probes 